\title{
EFICÁCIA E SELETIVIDADE DO HERBICIDA SIP 935 NO CONTROLE DE PLANTAS DANINHAS NO ALGODÃO
}

\author{
MORAES, Matheus Mendes Corrêa de ${ }^{1}$ \\ SENA FILHO, Antonio ${ }^{2}$
}

Recebido em: 2008-11-05

Aprovado em: 2009-02-02

ISSUE DOI: $10.3738 / 1982.2278 .154$

RESUMO: O algodão como todas as plantas cultivadas, sofre perdas quanti-qualitativa com a competição das plantas daninhas, principalmente, por água, luz, nutrientes. O objetivo do trabalho foi verificar a eficácia dos herbicidas no controle das plantas daninhas, e a seletividade destes às plantas de algodão. $\mathrm{O}$ experimento foi conduzido numa área da Fazenda Experimental da Faculdade "Dr. Francisco Maeda", localizada no município de Ituverava, SP, utilizando a variedade SS 9815 (Fabrika). A semeadura foi feita no dia 06/02/2007. O delineamento experimental utilizado foi em blocos ao acaso (DBC) com quatro repetições e quatro tratamentos. Avaliou-se, além do controle de plantas daninhas aos 15, 26, 68 Dias Após a Aplicação (DAA), o número de nós e a altura de cinco plantas por parcela aos 114 DAA. Os valores experimentais obtidos foram analisados estatisticamente utilizando o teste F para análise da variância, e o teste de Tukey para comparação das médias. A formulação SIP 935 foi eficaz no controle das plantas daninhas, aos 68 DAA, e apresentou boa seletividade à cultura do algodão, independentemente da dose utilizada.

Palavras-chave: Herbicida. Planta daninha. Algodão. Seletividade.

SUMMARY: The cotton as all the cultivated plants, it suffers competition with the harmful plants for water, it shines, nutritious and other. Therefore we have to control those undesirable plants, because they interfere a lot in the development of the implanted culture. With that, the intention of that work was to verify the efficiency of the herbicides exactly in the control of the harmful plants, and the selectivity of these the culture of the cotton. The experiment was driven in an area of Experimental Finance of University "Dr. Francisco Maeda", located in the municipal district of Ituverava, SP, using the variety SS 9815 (Fabrika), and the sowing was made on the $06 / 02 / 2007$. To the installation in the casualizado delineation (DBC) with four repetitions each treatment. The control of harmful plants was evaluated to the 15, 26, 68 Dias After the Application (DAA), considering the control through visual evaluations with a witness to the side, it was also evaluated the number of us and the height of five plants by portion to 114 DAA. After the application, the experimental data were analyzed estatisticamente by the test $\mathrm{F}$ for analysis of the variance and to the test of Tukey for comparison of the averages. Finally, the formulation SIP 935 was efficient in the control of the harmful plants, mainly to 68 DAA, and it presented good selectivity to the culture of the cotton, independently of the used dose.

Keywords: Herbicide. Plants harmful. Cotton. Selectivity.

\section{INTRODUÇÃO}

A presença das plantas daninhas é um fator biótico dos mais importantes na cultura do algodoeiro (Gossypium hirsutum), sendo considerada uma das culturas mais suscetíveis à interferência imposta pelas plantas daninhas, que pode ocasionar perda superior a $90 \%$ na

1 Engenheiro Agrônomo

2 Dr. em Agronomia. Professor FE/FAFRAM 
produtividade do algodão em caroço (FREITAS et al., 2002).

Dependendo da época e densidade em que ocorrem e das espécies presentes, competem por fatores limitantes do meio, tais como luminosidade, nutrientes e água. No final do ciclo podem interferir no processo de colheita, transporte e beneficiamento da produção, podendo afetar negativamente a qualidade da fibra colhida (IDE; IDE, 1997).

Devido à duração do período de prevenção da interferência, que pode se estender até 66 dias após a emergência (SALGADO et al., 2002) observaram que uma única operação de controle de plantas daninhas no início da implantação da cultura não é suficiente para prevenir infestações na época da colheita. Sendo assim, tratamentos com herbicidas aplicados na préemergência ou pós-emergência inicial podem ser considerados eficazes se eliminarem a competição inicial, até 45 a 60 dias após a emergência e mantiverem as plantas daninhas suficientemente pequenas para facilitar a aplicação e a ação de tratamentos com os herbicidas complementares aplicados em jato dirigido, normalmente entre 45 e 60 dias após a emergência da cultura.

Para conter os primeiros fluxos de emergência de plantas daninhas, pode-se recorrer a herbicidas pré-emergentes ou pós-emergentes iniciais. Entre as opções de pré-emergência está

o metolacloro ou s-metolacloro, um herbicida com ação residual pertencente ao grupo químico das cloroacetanilidas (SALGADO et al., 2002).

Alguns trabalhos se preocuparam em medir o potencial de redução de produtividade do algodão em função da presença das comunidades infestantes de plantas daninhas. Freitas et al. (2002) verificaram que a presença das plantas daninhas durante todo o ciclo da cultura reduziu o número de maçãs e a produtividade de algodão em caroço em $81 \%$.

Diante do exposto, o objetivo do presente estudo foi avaliar a eficácia no controle de plantas daninhas e a seletividade do herbicida SIP 935 na cultura do algodão.

\section{REVISÃO DE LITERATURA}

\subsection{IMPORTÂNCIA DO ALGODÃO}

A cultura do algodão (Gossypium hirsutum L.), planta da família Malvaceae, é considerada uma das principais cultivadas mundialmente, pois possui grande importância econômica por ser produtora de matéria-prima fornecida diretamente à indústria, e suas fibras dão origem a diversos produtos e subprodutos que gera muitos empregos diretos e indiretos do plantio ao comércio. 


\subsection{CONDIÇÕES E REGIÕES PARA CONDUÇÃO DA CULTURA DO ALGODÃO}

O algodão pode ser cultivado entre os paralelos $47^{\circ}$ de latitude norte e $30^{\circ}$ de latitude sul, em faixa com estações de 180 a 200 dias livres de geadas, com temperatura média acima de $20^{\circ} \mathrm{C}$, com dias predominantes ensolarados, precipitação pluviométrica de 500 a 1.500 mm/ano adequadamente distribuída (PASSOS, 1975).

É cultivado, no Brasil, em três macro-regiões: Norte-Nordeste (Tocantins, Maranhão, Piauí, Ceará, Rio Grande do Norte, Paraíba, Pernambuco, Alagoas e Bahia), a Centro-Oeste (Mato Grosso, Mato Grosso do Sul e Goiás) e a Sul-Sudeste (São Paulo, Paraná e Minas Gerais), nas quais encontram-se diferentes sistemas de produção, desde pequenas glebas, de agricultura familiar, até culturas empresariais, de alto nível tecnológico (FUZATTO et al., 2005).

\subsection{INTERAÇÃO ENTRE PLANTAS DANINHAS E A CULTURA DO ALGODÃo}

O algodoeiro, como qualquer planta cultivada, não se desenvolve isoladamente, mas com plantas de sua espécie e de espécies diferentes, em populações estreitamente espaçadas e intimamente relacionadas. $\mathrm{Na}$ fase de plântula, um espécime não altera o estabelecimento de outro da mesma ou de espécie diferente. A interferência de uma planta sobre outra se inicia quando a demanda, por um ou mais fatores de crescimento, é maior que o suprimento (RICHETTI et al., 2003).

\subsection{PREJUÍZOS E IMPLICAÇÕES CAUSADOS PELAS PLANTAS DANINHAS}

As plantas daninhas são, o fator biológico que mais interferem nesta cultura, causando prejuízos quantitativos e qualitativos na produção, prejudicando o rendimento do algodoeiro, o que faz elevar os custos de produção e diminuir o valor da fibra (LACA-BUENDIA, 1990).

Segundo Ashton; Mônaco (1991 apud RICHETTI et al., 2003) elas reduzem a produção das lavouras e aumentam seus custos de produção, mas podem, também, causar problemas de ordem social afetando a saúde, as residências, as áreas de recreação e a manutenção de áreas não cultivadas. Além desses aspectos, as plantas daninhas podem afetar a eficiência da terra, o controle de pragas e doenças, produtos agrícolas, o manejo da água na irrigação e a eficiência humana.

Para se ter uma idéia do prejuízo que pode causar, Victoria Filho (2000) cita os EUA, onde há grande uso de tecnologias de proteção de plantas disponíveis, no entanto, suas perdas com pragas, doenças e plantas daninhas chegaram a 35 bilhões de dólares anualmente, sendo 
gastos 10 bilhões todo ano em seu controle, totalizando um custo anual de 45 bilhões de dólares. Das perdas totais, $10 \%$ da produção agrícola são representadas por plantas daninhas, com valores até de 12 bilhões de dólares anuais, mais 6,2 bilhões de gastos no seu controle.

Conforme esquema proposto por Bleasdale (1960), modificado por Blanco (1972), e adaptado por Pitelli (1985), quanto maior o período de convivência múltipla, cultura e comunidade infestante, maior o grau de interferência, no entanto, o grau de interferência dependerá sobremaneira da época do ciclo do algodão em que este período ocorrer.

O intervalo de tempo entre a colheita e a semeadura de culturas em sucessão nos sistemas de plantio direto é muito importante. Normalmente, quanto maior for esse intervalo, maior será a possibilidade de germinação e de crescimento de plantas daninhas. Nesse caso, a quantidade e a qualidade dos restos culturais podem evitar ou diminuir a infestação das plantas daninhas (RUEDELL, 1995).

\subsection{ESTRATÉGIAS USADAS NO CONTROLE DAS PLANTAS DANINHAS}

\subsubsection{TÉCNICAS PARA CONTROLE DE PLANTAS DANINHAS}

Segundo Deuber (1999), o manejo de plantas daninhas no algodoeiro deve ser perfeitamente inserido no planejamento da lavoura como um todo, sendo fundamental o conhecimento prévio do potencial de infestação para se obter êxito, como as espécies e níveis de ocorrência. Para isso, necessita-se de levantamento e monitoramento preliminares nas áreas da cultura. O planejamento do manejo das plantas daninhas deve ter em mente a realidade conhecida a fim de se evitar desperdícios de recursos, de energia e de tempo. O ataque de plantas daninhas na cultura é considerado um dos mais significativos componentes da diminuição da produtividade da cultura do algodoeiro, pois na fase inicial do ciclo desta cultura, as plantas daninhas concorrem com ela na obtenção dos fatores de produção. Já no final do ciclo, prejudicam a qualidade da fibra e atrapalham a colheita (mecanizada ou manual). Plantas daninhas e a cultura convivendo juntas podem diminuir a produção em cerca de 68 a 95\%, além de outros inconvenientes na colheita.

Nesse sentido, afirmam Gelmini; Cruz (1983) que elas concorrem com o algodoeiro em luz, água, nutrientes e espaço, podendo causar prejuízos econômicos tanto em função da queda de produção, como por dificuldade que algumas espécies causam por ocasião da colheita, contribuindo para depreciação da qualidade do produto e constituindo-se em hospedeiros de pragas, doenças e/ou vírus, além de seu controle provocar o aumento do custo de produção e a conseqüiente redução na lucratividade. 


\subsection{2 ÉPOCA PARA CONTROLE DE PLANTAS DANINHAS}

No Brasil, Deuber (1999) demonstrou que nos primeiros 43 dias após a emergência a lavoura deve ficar livre da interferência das plantas daninhas, dependendo, no entanto, das espécies que ocorrem, sua freqüência, e das condições de clima e de solo.

Laca-Buendia; Alves-Faria (1978) constataram em Minas Gerais, melhor rendimento quando se manteve a cultura livre de competição durante 42 dias após a emergência, no Triângulo Mineiro, 56 dias após a emergência no Norte de Minas.

Já Gelmini; Cruz (1983) indicam que o mato não provoca perdas na produção do algodão quando é controlado do $20^{\circ}$ ao $45^{\circ}$ dia do seu ciclo vital.

Por outro lado, Cruz (1982 apud GELMINI; CRUZ, 1983) citam o período crítico como sendo nos primeiros 45-60 dias, com redução no rendimento, na altura da planta, no diâmetro do caule, no peso de 100 sementes e no peso de capulho.

\subsection{SELETIVIDADE DO HERBICIDA}

Os herbicidas atualmente em uso e que apresentam mecanismo de ação de inibição da fotossíntese são pertencentes aos grupos químicos: triazinas e triazinonas, uréias substituídas, amidas e benzotiadiazoles. O sítio de ação destes herbicidas é na membrana do cloroplasto, onde ocorre a fase luminosa da fotossíntese, mais especificamente no transporte de elétrons. Uma planta é susceptível aos herbicidas inibidores da fotossíntese se o herbicida acoplar-se ao composto $\mathrm{Q}_{\mathrm{B}}$ do componente do sistema fotossintético e, assim, impossibilitar a ocorrência do transporte do elétron até a plastoquinona. Dessa forma não existe a produção de ATP, pois a produção de elétrons é interrompida, bem como a produção de $\mathrm{NADPH}_{2}$ (CHRISTOFFOLETI, 1997).

A seletividade do herbicida é a base para o sucesso do controle químico de plantas daninhas na produção agrícola. É considerada como uma resposta diferencial de diversas espécies de plantas a um determinado herbicida. Quanto maior a diferença de tolerância entre a cultura e a planta daninha, maior a segurança de aplicação (OLIVEIRA J, 2001a).

A seletividade está relacionada à tolerância diferencial, sendo um fator relativo e particularmente característico para uma determinada interação herbicida, planta daninha, cultura e condições edafoclimáticas. Portanto, talvez o mais correto fosse julgar se determinado tratamento, e não um herbicida especificamente, é seletivo para determinada cultura. Por tratamento seletivo entende-se aquele que controla plantas daninhas sem afetar seriamente aquelas que são de interesse econômico (culturas) (OLIVEIRA JR, 2001a). 
Entre os fatores que determinam a seletividade encontram-se: i) fatores relacionados às características do herbicida, ou ao método de aplicação como dose, formulação, localização espacial ou temporal do herbicida em relação à planta, ii) fatores relacionados às características das plantas como seletividade associada à retenção e à absorção diferencial (idade das plantas, cultivar, tamanho da semente ou estrutura de propagação vegetativa); seletividade associada a translocação diferencial e; seletividade associada ao metabolismo diferencial (detoxificação); iii) antídotos (OLIVEIRA J, 2001a).

A aplicação dos herbicidas pertencentes a este mecanismo de ação resulta na perda de praticamente todos os pigmentos das plantas susceptíveis, resultando numa aparência "albina". O primeiro composto identificado deste grupo e usado na agricultura foi o clomazone, usado pela primeira vez nos EUA (OLIVEIRA J, 2001a).

\section{MATERIAL E MÉTODOS}

O experimento foi conduzido entre 06/02/2007 e 01/06/2007 numa área da Fazenda Experimental da Faculdade "Dr. Francisco Maeda", localizada no município de Ituverava, SP. Os resultados da análise físico-química de uma amostra composta do solo encontram-se descritos na Tabela 1 e 2 , respectivamente.

TABELA 1 - Resultado da analise química de uma amostra composta de solo coletado no local do experimento.

\begin{tabular}{cccccccccc}
\hline $\mathrm{pH}$ & $\mathrm{M} . \mathrm{O}$ & $\mathrm{P}$ & $\mathrm{K}$ & $\mathrm{Ca}$ & $\mathrm{Mg}$ & $\mathrm{H}+\mathrm{Al}$ & $\mathrm{SB}$ & $\mathrm{T}$ & $\mathrm{V}$ \\
\cline { 5 - 8 } $\mathrm{CaCl}_{2}$ & $\mathrm{~g} / \mathrm{dm}^{3}$ & resina & \multicolumn{7}{c}{$\mathrm{mmolc}_{\mathrm{n}} \mathrm{dm}^{3}$} \\
\hline 4,7 & 63 & 26 & 1,6 & 24 & 7 & 47 & 33 & 80 & 41 \\
\hline
\end{tabular}

TABELA 2 - Resultado da análise granulométrica de uma amostra composta de solo coletado no local do experimento.

\begin{tabular}{cccc}
\hline Argila $(\mathrm{g} / \mathrm{kg})$ & Limo $(\mathrm{g} / \mathrm{kg})$ & Areia $(\mathrm{g} / \mathrm{kg})$ & Classe Textural \\
\hline 408 & 257 & 325 & argilosa \\
\hline
\end{tabular}

\subsection{PLANTIO E CONDUÇÃO DA CULTURA}

O algodão variedade SS 9815 (Fabrika) foi semeado no dia 06/02/2007 com espaçamento de $0,90 \mathrm{~m}$ entrelinhas. A área foi preparada no sistema convencional com aração seguida de gradagens. A adubação de plantio constou da aplicação de $250 \mathrm{~kg} / \mathrm{ha}$ da fórmula 
04-14-08 e a adubação de cobertura foi realizada aos 43 dias após a semeadura, aplicando-se $200 \mathrm{~kg} / \mathrm{ha}$ de uréia. A aplicação de fungicida e inseticida foi realizada obedecendo critérios técnicos, preventivamente e após monitoramento no campo.

\subsection{TRATAMENTOS}

Os tratamentos consistiram da aplicação de quatro doses crescentes do herbicida SIP 935, além de um tratamento padrão, Dual Gold, uma testemunha no limpo e outra sem controle. Para melhor visualização os mesmos encontram-se descritos na Tabela 3.

TABELA 3 - Doses utilizadas para a composição dos tratamentos.

\begin{tabular}{cccc}
\hline Tratamento & Nome Técnico & Dose (g i.a./ha) & Dose (g ou ml p.c./ha) \\
\hline 1 & Metolacloro $^{1}$ & 1200 & 1250 \\
2 & Metolacloro & 1440 & 1500 \\
3 & Metolacloro & 1680 & 1750 \\
4 & Metolacloro & 1920 & 2000 \\
5 & S-metolacloro & & 1500 \\
6 & Testemunha capinada $^{2}$ & 1440 & -- \\
7 & Testemunha mato & -- & -- \\
\hline
\end{tabular}

Informações técnicas sobre os produtos utilizados:

Marca comercial: Dual Gold

Nome comum: S-Metolacloro

Tipo Formulação: concentrado emulsionável

Concentração: $960 \mathrm{~g} / \mathrm{l}$

Grupo químico: cloroacetanilidas

Classe Toxicológica: classe I - extremamente tóxico

Marca comercial: SIP 935

Nome comum: Metolacloro

Tipo Formulação: concentrado emulsionável

Concentração: 960 g/l

Grupo químico: cloroacetanilidas

Classe Toxicológica: não definida 


\subsection{TECNOLOGIA DE APLICAÇÃO}

A aplicação dos tratamentos foi realizada em pré-emergência das plantas daninhas com pulverizador costal à pressão constante $\left(\mathrm{CO}_{2}\right)$, munido de barra com 4 pontas XR11002 reguladas com 3,8 bar de pressão para distribuir $200 \mathrm{~L} / \mathrm{ha}$ de calda. A data e o horário da aplicação, bem como as condições dos principais elementos climáticos num momento durante a aplicação encontram-se na Tabela 4.

TABELA 4 - Data, horário e condições dos principais elementos climáticos num momento durante a aplicação.

\begin{tabular}{ccccccc}
\hline \multirow{2}{*}{ Data } & \multicolumn{2}{c}{ Horário } & \multicolumn{2}{c}{ Temp. $\left({ }^{\circ} \mathrm{C}\right)$} & U.R & Vento \\
\cline { 2 - 5 } & início & fim & $\mathrm{Ar}$ & solo & (ox) & $(\mathrm{m} / \mathrm{s})$ \\
\hline $07 / 02 / 07$ & $11: 00$ & $11: 40$ & 28 & 29,3 & 75 & $<1,6$ \\
\hline
\end{tabular}

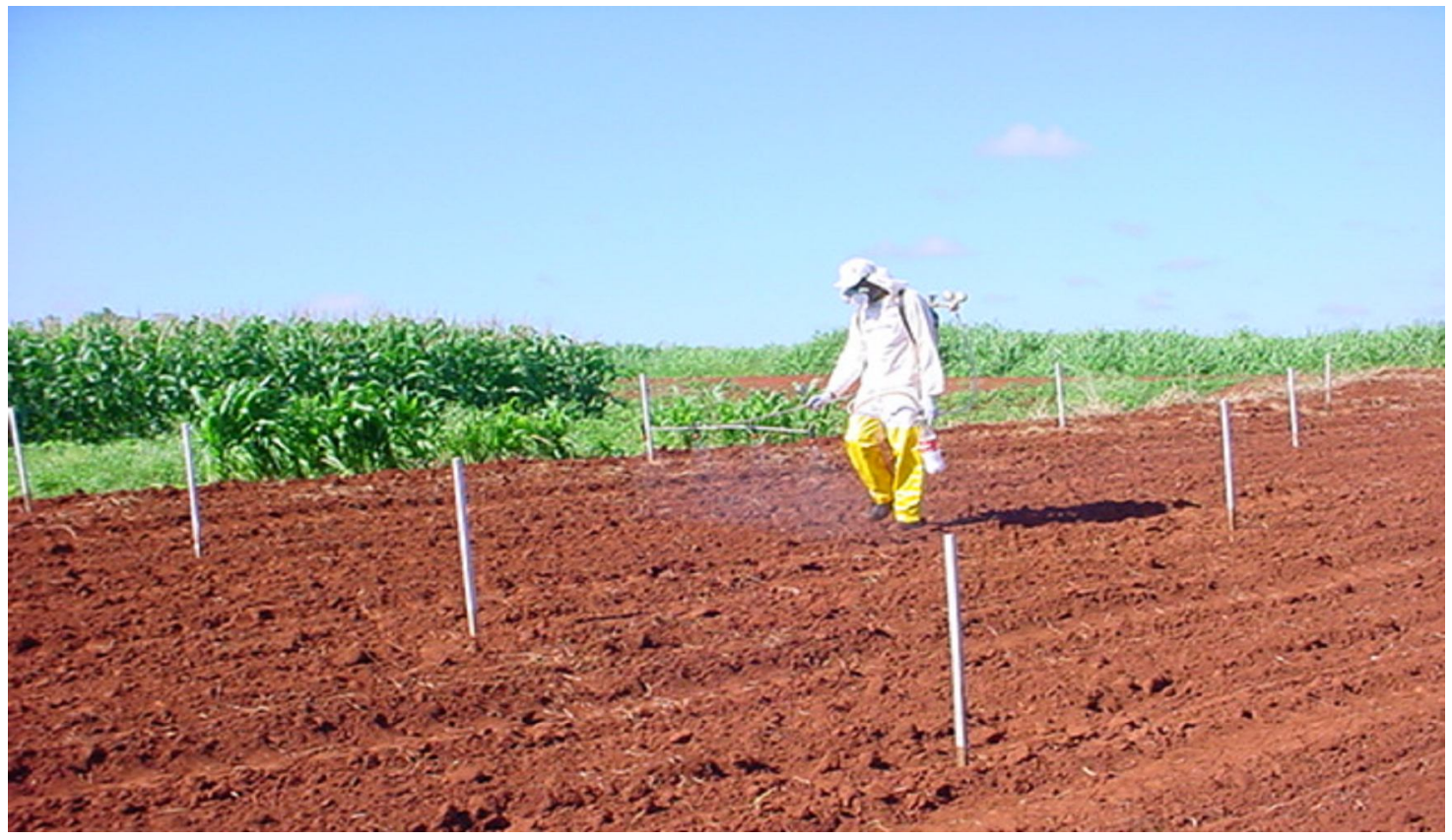

Foto do dia da aplicação do herbicida.

\subsection{DELINEAMENTO EXPERIMENTAL E DIMENSÕES DAS PARCELAS}

O experimento foi instalado no delineamento em blocos ao acaso com quatro repetições por tratamento. As parcelas tiveram como dimensões 3,6m de largura por $5 \mathrm{~m}$ de comprimento. 


\subsection{AVALIAÇÕES}

O controle das plantas daninhas foi avaliado aos 15, 26, 68, DAA (dias após a aplicação), atribuindo-se porcentagem de controle em relação à testemunha, por meio de avaliações visuais. Também foi avaliado o número de nós e altura de cinco plantas por parcela aos 114 DAA, com a finalidade de verificar se houve fitotoxicidade.

\subsection{ANÁLISE ESTATÍSTICA}

Os dados obtidos foram submetidos à análise de variância pelo teste $\mathrm{F}$ e as médias comparadas pelo teste de Tukey ao nível de $5 \%$ de probabilidade quando pertinente.

\section{RESULTADOS E DISCUSSÃO}

A infestação da área foi natural e as principais espécies que compuseram a comunidade de plantas daninhas foram: apaga-fogo (Alternanthera tenella), capim-carrapicho (Cenchrus. Echinatus) e caruru (Amaranthus hybridus) que juntos responderam, em média por $40 \%, 25 \%$ e $25 \%$, respectivamente, em relação à cobertura da área nas testemunhas sem aplicação, e os $10 \%$ restantes foram divididos em outras plantas que não foram avaliadas.

O controle de A. tenella pode ser analisado pelos dados contidos na Tabela 5. Verificou-se que aos 15 DAA os resultados proporcionados pelos tratamentos químicos, foram estatisticamente semelhantes com excelente controle, principalmente para doses iguais e superiores a 1500 g p.c./ha do SIP 935 e para o S-metolacloro. Com a evolução do experimento os níveis de controle apresentaram redução, sendo que aos 26 DAA observou-se uma leve inferioridade entre a menor dose de SIP 935, quando comparado com suas menores doses e/ou com o S-metolacloro. Entre 26 DAA e 68 DAA também foi observado redução no controle que se situou entre $71 \%$ e $81 \%$ não havendo, entretanto, diferenciação estatisticamente significativa entre os tratamentos químicos 
TABELA 5 - Porcentagem de controle de A. tenella ao longo do tempo e em função dos tratamentos.

\begin{tabular}{cccccc}
\hline & Descrição do tratamento & \multicolumn{3}{c}{ Porcentagem de controle } \\
\hline $\mathrm{N}^{\mathrm{o}}$ & Produto & Dose & 15 DAA & 26 DAA & 68 DAA \\
& & (g ou ml p.c./ha) & & & \\
\hline 1 & Metolacloro & 1250 & 86 & $81 \mathrm{~B}$ & 72 \\
2 & Metolacloro & 1500 & 92 & $88 \mathrm{AB}$ & 80 \\
3 & Metolacloro & 1750 & 94 & $92 \mathrm{~A}$ & 81 \\
4 & Metolacloro & 2000 & 92 & $90 \mathrm{AB}$ & 71 \\
5 & S-metolacloro & 1500 & 92 & $89 \mathrm{AB}$ & 76 \\
6 & Testemunha capinada & -- & 100 & 100 & 100 \\
7 & Testemunha & -- & 0 & 0 & 0 \\
\hline \multicolumn{7}{c}{ Trat_F } & & $2,02 \mathrm{~ns}$ & $3,62 * *$ & $0,73 \mathrm{~ns}$ \\
& CV(\%) & & 5 & 5 & 13 \\
\hline
\end{tabular}

Tédias seguidas de mesma letra não diferem significativamente entre si ao nível de 5\% de probabilidade pelo teste de Tukey; ns não significativo pelo teste $\mathrm{F}$ ao nível de $5 \%$ de probabilidade; ** significativo pelo teste $\mathrm{F}$ ao nível de $5 \%$ de probabilidade.

Para o $C$. echinatus em nenhuma época de avaliação observou-se diferenciação nos resultados de controle proporcionado pelos diferentes tratamentos químicos que fosse estatisticamente significativa. De um modo geral os maiores níveis de controle foram observados até 26 DAA, quando a formulação SIP 935 nas doses iguais ou superiores a 1500 g p.c./ha e o S-metolacloro apresentaram controle igual ou superior 90\%. Entre 26 DAA e 68 DAA observou-se maior redução de controle pelos tratamentos químicos, no entanto os níveis ainda permaneceram bons, entre $81 \%$ e $85 \%$, quando os tratamentos foram S-metolacloro ou SIP 935 em doses iguais ou superiores a 1500 g p.c./ha. 
TABELA 6 - Porcentagem de controle de $C$. echinatus ao longo do tempo e em função dos tratamentos.

\begin{tabular}{cccccc}
\hline & \multicolumn{2}{c}{ Descrição do tratamento } & \multicolumn{2}{c}{ Porcentagem de controle } \\
\hline $\mathrm{N}^{\mathrm{o}}$ & Produto & $\begin{array}{c}\text { Dose } \\
\text { (g ou ml p.c./ha) }\end{array}$ & 15 DAA & 26 DAA & 68 DAA \\
\hline 1 & Metolacloro & 1250 & 84 & 82 & 71 \\
2 & Metolacloro & 1500 & 92 & 91 & 85 \\
3 & Metolacloro & 1750 & 97 & 94 & 81 \\
4 & Metolacloro & 2000 & 95 & 90 & 84 \\
5 & S-metolacloro & 1500 & 93 & 93 & 81 \\
6 & Testemunha capinada & -- & 100 & 100 & 100 \\
7 & Testemunha & -- & 0 & 0 & 0 \\
\hline & Trat_F & & $1,78 \mathrm{~ns}$ & $1,31 \mathrm{~ns}$ & $0,43 \mathrm{~ns}$ \\
& CV(\%) & & 8 & 9 & 21 \\
\hline
\end{tabular}

${ }^{1}$ Médias seguidas de mesma letra não diferem significativamente entre si ao nível de 5\% de probabilidade pelo teste de Tukey; ns não significativo pelo teste $\mathrm{F}$ ao nível de $5 \%$ de probabilidade; ${ }^{*} *$ significativo pelo teste $\mathrm{F}$ ao nível de $5 \%$ de probabilidade.

Em relação ao controle de $A$. hybridus, verificou-se que até 26 DAA todos os tratamentos químicos apresentaram excelente controle, acima de 90\%. Aos 26 DAA observou-se que doses extremas, da formulação SIP 935 tenderam a apresentar menor controle desta espécie. Entretanto, entre 26 DAA e 68 DAA os níveis de controle apresentaram redução mantendo-se, ainda num nível satisfatório, entre $88 \%$ e $98 \%$ e sem diferenciação estatisticamente significativa.

Ao analisarmos o resultado final de controle das espécies deve-se considerar, que na cultura do algodão os tratamentos em pré-emergência até então disponíveis requerem uma segunda intervenção que normalmente são impostos antes da época da realização da última avaliação de controle deste experimento. 
TABELA 7 - Porcentagem de controle de A. hybridus ao longo do tempo e em função dos tratamentos.

\begin{tabular}{|c|c|c|c|c|c|}
\hline \multicolumn{3}{|c|}{ Descrição do tratamento } & \multicolumn{3}{|c|}{ Porcentagem de controle } \\
\hline $\mathrm{N}^{\mathrm{o}}$ & Produto & $\begin{array}{c}\text { Dose } \\
\text { (g ou ml p.c./ha) }\end{array}$ & $15 \mathrm{DAA}$ & 26 DAA & $\begin{array}{c}68 \\
\text { DAA }\end{array}$ \\
\hline 1 & Metolacloro & 1250 & 94 & $92 \mathrm{~B}$ & 89 \\
\hline 2 & Metolacloro & 1500 & 100 & $100 \mathrm{~A}$ & 90 \\
\hline 3 & Metolacloro & 1750 & 100 & $99 \mathrm{~A}$ & 96 \\
\hline 4 & Metolacloro & 2000 & 99 & $94 \mathrm{AB}$ & 88 \\
\hline 5 & S-metolacloro & 1500 & 100 & $100 \mathrm{~A}$ & 98 \\
\hline 6 & Testemunha capinada & -- & 100 & 100 & 100 \\
\hline 7 & Testemunha & -- & 0 & 0 & 0 \\
\hline & $\begin{array}{l}\text { Trat_F } \\
\mathrm{CV}(\%)\end{array}$ & & $\begin{array}{c}2,24 \mathrm{~ns} \\
3\end{array}$ & $\begin{array}{c}5,69 * * \\
3\end{array}$ & $\begin{array}{c}2,07 \mathrm{~ns} \\
7\end{array}$ \\
\hline
\end{tabular}

${ }^{\top}$ Médias seguidas de mesma letra não diferem significativamente entre si ao nível de 5\% de probabilidade pelo teste de Tukey; ns não significativo pelo teste $\mathrm{F}$ ao nível de 5\% de probabilidade; ** significativo pelo teste $\mathrm{F}$ ao nível de 5\% de probabilidade.

Em relação ao desenvolvimento da planta de algodão, representado pela altura e número de nós (Tabela 8), verificou-se que nenhum dos tratamentos químicos prejudicou o desenvolvimento das plantas de algodão, independentemente do parâmetro considerado, da formulação e da dose empregada indicando que as doses testadas da formulação de SIP 935 apresentaram seletividade suficiente para não prejudicar o algodoeiro.

TABELA 8 - Número de nós e altura das plantas de algodão em função dos tratamentos experimentais

\begin{tabular}{ccccc}
\hline \multirow{2}{*}{ Tratamentos } & \multirow{2}{*}{ Produtos } & Doses & \multicolumn{2}{c}{ Época de avaliação } \\
\cline { 4 - 5 } & & 1250 & 114 DAA \\
\cline { 4 - 5 } & Metolacloro & Altura (cm) & Número de nós \\
\hline 1 & Metolacloro & 1500 & 98,7 & 13,15 \\
3 & Metolacloro & 1750 & 100,2 & 12,65 \\
4 & Metolacloro & 2000 & 96,05 & 13,3 \\
5 & S-metolacloro & 1500 & 91,65 & 12,65 \\
6 & Test. capinada & --- & 87,15 & 12,05 \\
7 & Testemunha mato & --- & 101,75 & 11,5 \\
& Valor_F & & $1,68 \mathrm{~ns}$ & $1,1,8$ \\
\hline
\end{tabular}

\footnotetext{
${ }^{1}$ Médias seguidas de mesma letra não diferem significativamente entre si ao nível de 5\% de probabilidade pelo teste de Tukey; ns - não significativo pelo teste $\mathrm{F}$ ao nível de 5\% de probabilidade; ** significativo pelo teste $\mathrm{F}$ ao nível de 5\% de probabilidade.
} 


\section{CONCLUSÃO}

Diante do exposto, pôde-se concluir que:

- a formulação SIP 935 mostrou-se eficiente para o controle de C. echinatus, A. tenella e A. hybridus, apresentando bom controle até 68 DAA, principalmente quando utilizado em doses iguais ou superiores a $1500 \mathrm{~g}$ p.c./ha, equiparando-se ao proporcionado pelo S-metolacloro (Dual Gold);

- a formulação SIP 935 apresentou boa seletividade à cultura do algodão, pois independentemente da dose não afetou negativamente o desenvolvimento em altura e número de nós, assim como o S-metolacloro (Dual Gold).

\section{REFERÊNCIAS}

ASHTON, F. M.; MÔNACO, T. J. Weed science. In: RICHETTI, A. Recomendações técnicas para o uso de herbicidas no controle de plantas daninhas na cultura do algodoeiro no cerrado. Embrapa Algodão, jan. 2003. (Sistema de produção, 2).

BLANCO, H. G. A importância dos estudos ecológicos nos programas de controle de plantas daninhas. O Biológico, São Paulo, v.38, n.10, p.343-350, 1972.

BLEASDALE, J. K. A. Studies on plant competition. In: HARPER, J. L. The biology of weeds. Oxford: Blackwell Scientific, 1960. p. 133-142.

CHRISTOFFOLETI, P. J. Resistência de plantas daninhas aos herbicidas. In: SIMPÓSIO SOBRE HERBICIDAS E PLANTAS DANINHAS, 1., Dourados: EMBRAPA, 1997. p. 7594.

CRUZ, L. S. P. Manejo de plantas daninhas em culturas anuais. 1982. In: GELMINI, G. A.; CRUZ, L. S. P. Controle de plantas daninhas na cultura do algodão. Campinas: CATI, 1983. (Boletim técnico, n. 178).

DEUBER, R. Manejo integrado de plantas infestantes na cultura do algodoeiro. In: CIA, E.; FREIRE, E. C.; SANTOS, W. J. dos. Cultura do algodoeiro. Piracicaba: Potafos, 1999. p. 101-103.

FREITAS, R. S. et al. Interferência de plantas daninhas na cultura de algodão em sistema de plantio direto. Planta Daninha, v. 20, n. 2, p. 197-205, 2002.

FUZATTO, M. G. et al. Algodão (Gossypium hirsutum L.). 2005. Disponível em:

<http://www.iac.sp.gov.br/Tecnologias/Algodao/algodao.htm>. Acesso em: 10 nov. 2007. 
GELMINI, G. A.; CRUZ, L. S. P. Controle de plantas daninhas na cultura do algodão. Campinas: CATI, 1983. (Boletim técnico, n. 178).

IDE, M. A.; IDE, I. Colheita mecanizada do algodão. In: ENCONTRO SOBRE A CULTURA DO ALGODOEIRO, 1. Anais... Ituverava, 1997. p. 105-120. Faculdade de Agronomia "Dr. Francisco Maeda". Fundação Educacional de Ituverava.

LACA-BUENDIA, J. P.; ALVES-FARIA, E. Tratos culturais do algodoeiro. Informe Agropecuário, Belo Horizonte, v. 41, p. 22-33, 1978.

LACA-BUENDIA, J. P. Controle de plantas daninhas em algodoeiro. Informe Agropecuário, v. 15, n. 166, p. 3747, 1990.

OLIVEIRA Jr., R. S. de. Seletividade de herbicidas para culturas e plantas daninhas. In: OLIVEIRA Jr., R. S. de; CONSTANTIN, J.(Coord.). Plantas daninhas e seu manejo. Guaíba: Agropecuária, 2001b. p. 291-314.

Mecanismos de ação de herbicidas. In: OLIVEIRA JÚNIOR., R. S. de; CONSTANTIN, J.(Coord.). Plantas daninhas e seu manejo. Guaíba: Agropecuária, 2001a. p.207-260.

PASSOS, M. G. O fator clima na cultura do algodão. Anuário Agrícola Brasileiro, n. 17, p. 79-83, 1975.

PITELLI, R. A. Interferência das plantas daninhas em culturas agrícolas. Informe Agropecuário, v. 11, n. 129, p. 16-27, 1985.

RODRIGUES, B. N.; ALMEIDA, F. S. (Ed.). Guia de herbicidas. Londrina: Ed. dos autores, 1995. $675 \mathrm{p}$.

RUEDELL, J. Dessecação e controle de plantas infestantes no sistema plantio direto. In: SEMINÁRIO INTERNACIONAL DO SISTEMA PLANTIO DIRETO, 1., Passo Fundo, 1995. Resumos... Passo Fundo: EMBRAPA, CNPT, 1995. p.21-27.

SALGADO, T. P. et al. Períodos de interferência das plantas daninhas na cultura do algodoeiro (Gossypium hirsutum). Planta Daninha, v. 20, n. 3, p. 373-379, 2002.

VICTÓRIA FILHO, R. Estratégias de manejo de plantas daninhas. In: ZAMBOLIM, L. Manejo integrado: doenças, pragas e plantas daninhas. Viçosa: UFV, 2000. p. 349-353. 